\title{
1 Direct and indirect effects of heatwaves on a coral reef fishery
}

2 Running title: Effects of heatwaves on a coral reef fishery

3 Christopher J Brown ${ }^{1,}{ }^{*}$, Camille Mellin ${ }^{2,3}$, Graham J Edgar ${ }^{2}$, Max D Campbell ${ }^{1}$, Rick D Stuart-Smith ${ }^{2}$

4 1. Australian Rivers Institute - Coasts and Estuaries, School of Environment and Science, Griffith University,

5 Nathan, 4111, Queensland, Australia

2. Institute for Marine and Antarctic Studies, University of Tasmania, Hobart, Tasmania 7001, Australia.

3. The Environment Institute and School of Biological Sciences, University of Adelaide, Adelaide, South Australia 5005, Australia.

* Corresponding author. chris.brown@griffith.edu.au, ph: +61 (0)7 37359268

\section{Abstract}

Marine heatwaves are increasing in frequency and intensity, and indirectly impacting coral reef fisheries through bleaching-induced degradation of live coral habitats. Marine heatwaves also affect fish metabolism and catchability, but such direct effects of elevated temperatures on reef fisheries are largely unknown. We investigated direct and indirect effects of the devastating 2016 marine heatwave on the largest reef fishery operating along the Great Barrier Reef (GBR). We used a combination of fishery-independent underwater census data on coral trout biomass (Plectropomus and Variola spp.) and catch-per-unit-effort (CPUE) data from the commercial fishery to evaluate changes in the fishery resulting from the 2016 heatwave. The heatwave caused widespread, yet locally patchy, declines in coral cover, but we observed little effect of local coral loss on coral trout biomass. Instead, a pattern of decreasing biomass at northern sites and stable or increasing biomass at southern sites suggested a direct response of populations to the heatwave. Analysis of the fishery-independent data and CPUE found that in-water coral trout biomass estimates were positively related to CPUE, and that coral trout catch rates increased with warmer temperatures. Temperature effects on catch rates were consistent with the thermal affinities of the multiple species contributing to this fishery. Scaling-up the effect of temperature on coral trout catch rates across the region suggests that GBR-wide catches were $18 \%$ higher for a given level of effort during the heatwave year relative to catch rates under the mean temperatures in the preceding 6 years. These results highlight a potentially large effect of heatwaves on catch rates of reef fishes, independent of changes in reef habitats, that can add substantial uncertainty to estimates of stock trends inferred from fishery-dependent (CPUE) data. Overestimation of CPUE could initiate declines in reef fisheries that are currently fully exploited, and threaten sustainable management of reef stocks.

Key words: Heatwave, coral reef fishery, coral trout, coral bleaching, catchability, Bayesian modelling, climate change. 
Rapid changes in climate are an important driver of the exploitation status of fisheries (Brander, 2010; Free et al., 2019), with extreme climate events implicated in both fisheries collapses and unexpected productivity booms (Belhabib, Dridi, Padilla, Ang, \& Le Billon, 2018). Marine heatwaves, in particular, are increasing in frequency and intensity under climate change, impacting the habitats and ecosystems that regulate the productivity of fisheries (Graham et al., 2007; Lefcheck, Wilcox, Murphy, Marion, \& Orth, 2017; Oliver et al., 2018; Robinson et al., 2019; Smale et al., 2019) and directly affecting the behaviour, ecological interactions, spawning, survival and the distribution of fishery species (Auth, Daly, Brodeur, \& Fisher, 2018; Caputi et al., 2019). Heatwaves can impact fisheries productivity through the direct effects of temperature on the physiology of target species and indirect effects that play out through impacts on their ecosystem, but these are seldom distinguished.

Coral reef fisheries support millions of livelihoods globally (Burke, Reytar, Spalding, \& Perry, 2011), but their productivity may be jeopardized by effects of heatwaves on fish physiology and behaviour (Pratchett et al., 2017), foodwebs (Hempson et al., 2017; Rogers, Blanchard, \& Mumby, 2018), and through the loss of coral habitats that are sensitive to heatwaves (Hughes et al., 2018; Stuart-Smith, Brown, Ceccarelli, \& Edgar, 2018). Coral habitat loss is the most frequently observed cause of indirect heatwave impacts on reef fisheries to date (Bell et al., 2013; Graham et al., 2007; Robinson et al., 2019). Coral death causes shifts in benthic community composition (Darling et al., 2019; Hughes et al., 2018) and changes in structural complexity (Ferrari et al., 2016), both of which are important for early life-stages of reef fishery species (Graham \& Nash, 2013; Wen, Pratchett, Almany, \& Jones, 2013). The effects of warming on the physiology and ecology of fishes may also impact reef fisheries, by directly changing survival, growth, activity patterns, and therefore the availability of fish to the fishery (Pratchett et al., 2017), or indirectly by affecting habitat and prey availability (Hempson et al., 2017). The direct effects of heatwaves on reef fishes are strongly supported by experimental studies (Pratchett et al., 2017), but effects of contemporary heatwaves on reef fisheries remain poorly understood.

The impacts of heatwaves on the growth and distribution of fish stocks are likely to be confounded with other environmental changes, because these impacts will play out over multiple years. Short-term impacts of heatwaves on fisheries species may be expected through sudden declines in survival and behavioural change. In particular, behavioural responses of reef fishes to changes in temperature can be strong (Pratchett et al., 2017). These behavioural responses to temperature change can affect the catchability of fish by fisheries, where catchability is commonly defined as a scaling constant relating catch-per-unit-effort (CPUE) to biomass (Patterson, Pitcher, \& Stokes, 1993; Wilberg, Thorson, Linton, \& Berkson, 2009). Importantly, catchability can change over time and space, depending on a number of behavioural attributes of the fishes, including changes in activity, feeding rates or escape responses - most of which are temperature-dependent (e.g. Bacheler \& Shertzer, 2020). If catchability increases go unnoticed, a fishery 
may maintain catch-per-unit-effort even as biomass declines, potentially resulting in a sudden unexpected collapse (e.g. Hamilton et al., 2016). For example, overfishing of the chub mackerel (Scomber japonicus) fishery off Ecuador was associated with temperature-driven changes in catchability that caused increases in fishing mortality, despite effort remaining consistent over years (Patterson et al., 1993). Temperature is known to affect the catchability of some reef species (Bacheler \& Shertzer, 2020), though it is not clear whether heatwave events could induce changes in catchability. Such effects of temperature on catchability might be expected for reef fishes, given their sensitivity to temperature change (Pratchett et al., 2008).

Here we analysed changes in the in-water biomass and catch rates of coral trout (Plectropomus and Variola spp.), the major targets of the largest commercial reef fish fishery along Australia's Great Barrier Reef (GBR). The GBR is a World Heritage area and is managed through an extensive marine park and a number of fisheries regulations (Hopf, Jones, Williamson, \& Connolly, 2016; Little et al., 2011). The major values of the reef for biodiversity, tourism and fisheries are increasingly under threat from repeated marine heatwaves that have caused mass bleaching events, and severe cyclones (GBRMPA, 2019; Mellin et al., 2019). The 2016 pan-tropical heatwave caused coral bleaching on $60 \%$ of the GBR's reefs, with widespread coral mortality subsequently observed (Hughes et al., 2018; Stuart-Smith et al., 2018). Changes in fish community structure were also evident along the entire GBR, much of which appeared to be in direct response to warming rather than a result of coral mortality (Stuart-Smith et al., 2018), although coral mortality also had clear impacts, particularly on small coral-dependent reef fishes (Richardson, Graham, Pratchett, Eurich, \& Hoey, 2018). It is not clear whether the heatwave also affected reef fisheries. The reef line fishery is the largest fishery operating in the GBR marine park and the main targets are coral trout. Coral trout physiology and behaviour are sensitive to changes in temperature (Pratchett et al., 2017), but they also respond to changes in prey fish abundance (Hempson et al., 2017) and some species are dependent on coral habitats for settlement (Wen et al., 2013). Like many other reef fishery targets, the multiple potential responses of coral trout to elevated temperatures imply a high likelihood of impacts of the 2016 heatwave on the fishery.

We used underwater visual census (UVC) data from 65 reef sites on the GBR that were surveyed before and after the 2016 heatwave along with CPUE data from the Queensland line fishery, enabling a concurrent assessment of how the heatwave and associated habitat changes affected both coral trout populations and the fishery. We first hypothesized that the heatwave decreased coral trout biomass on northern reefs, where (1) temperatures exceeded those found at the warmest sites most of the coral trout species have previously been recorded (Stuart-Smith, Edgar, \& Bates, 2017; Wolanski, Andutta, Deleersnijder, Li, \& Thomas, 2017), and (2) loss of coral habitat was greatest (Stuart-Smith et al., 2018). Warming beyond optimal temperatures of $25-31^{\circ} \mathrm{C}$ also affects multiple physiological and behavioural traits for $P$. leopardus, which together would be expected to reduce survival rates (Johansen et al., 2015; Pratchett et al., 2017). Therefore, we predicted that temperature rises above $\sim 27^{\circ} \mathrm{C}$ would cause declines in biomass the year after 
the heatwave. Second, we hypothesized that warming may increase the catchability of fish in the line fishery. We base this hypothesis on experimental studies of coral trout thermal performance curves, which indicate they eat more at warmer temperatures (Johansen et al., 2015), so they may be more likely to take a lure or baited line. We then used the empirical analysis on the response of the fishery to the heat wave to scale-up the data and estimate the effect of the heatwave on the annual catch of the fishery. We ultimately aimed to determine how the direct and indirect effects of heatwaves on coral reef fisheries may help or hinder the productivity and ongoing sustainable management of reef fish stocks.

\section{Methods}

Our analysis was divided into three stages. To address the first hypothesis, we used the fisheryindependent UVC data to model the association between coral trout biomass and environmental covariates, including the heatwave anomaly and coral habitat. We then predicted coral trout biomass at the scale of the entire GBR reef line fishery and analysed the association between predicted biomass and fishery-dependent catch-per-unit-effort data. This analysis allowed us to test the hypothesis that warming would increase catchability of coral trout. Finally, we estimated the effect of the heatwave on catches at the scale of the entire GBR.

Analysis of fishery-independent data on coral trout biomass from the underwater visual census

Underwater visual censuses were conducted from 2010 to 2017, comprising 117 surveys before the 2016 heatwave and 124 surveys at the same sites between 6 months and 1 year after the heatwave (fig. 1a) (Stuart-Smith et al., 2018). The UVC methodology followed the standardized Reef Life Survey protocol (Edgar \& Stuart-Smith, 2014), as detailed in an online methods manual (www.reeflifesurvey.com). The methods consist of diver counts and size estimates of reef fishes observed along $50 \mathrm{~m}$ transect lines ('surveys') in duplicate $5 \mathrm{~m}$ wide belts (total area per transect $=500 \mathrm{~m}^{2}$ ). Biomass was calculated from fish length and counts using species-specific length-weight coefficients obtained from FishBase (www.fishbase.org) and a correction factor for diver-bias in estimation of size, as used in previous studies with these data (Edgar, Barrett, \& Morton, 2004). Although UVC data distinguished seven species of coral trout that are caught by fishers (dominated by Plectropomus leopardus, but also including four other Plectropomus spp. and two Variola spp.), these are not distinguished in the fishery statistics. Therefore, UVC data on coral trout species were aggregated for the main analyses to be consistent with the fisheries data. 

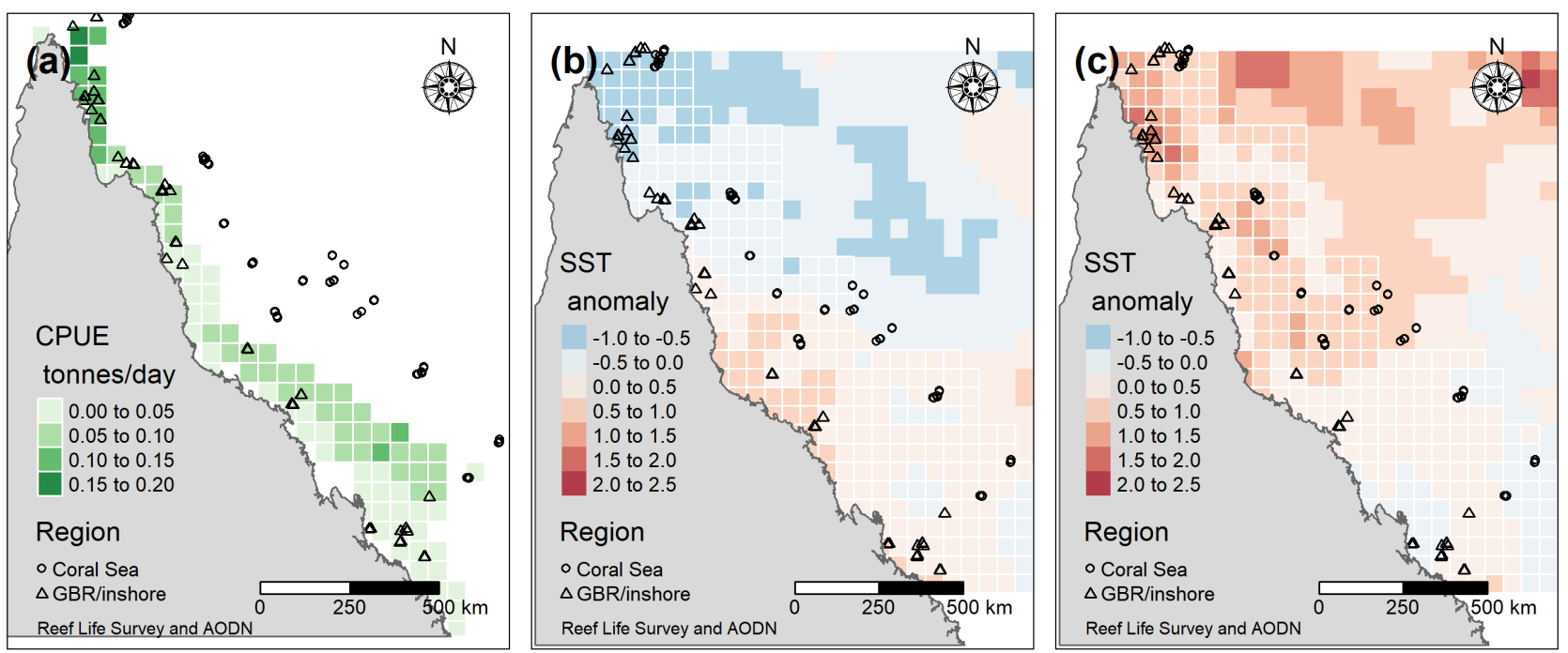

Figure 1 (A) Map of the mean annual catch-per-unit-effort in the line fishery (2007-2016) across the Great Barrier Reef and the locations of the UVC sites (note that sites outside of the GBR in the western Coral Sea shown were used for the supplemental analysis of species composition, but are outside of the limits of the fishery, so were not used for matching to the fisheries data), (B) SST anomaly for 2015 with sites surveyed before the heatwave, and (C) SST anomaly for 2016 with sites surveyed after the heatwave.

We modelled coral trout biomass from the UVC in response to the heatwave and other environmental covariates using a Bayesian generalized linear mixed effects model (GLMM). There was a high frequency of zero biomasses observed in the UVC, so we used a log-normal hurdle model. The hurdle model modelled presence-absence of coral trout on surveys using a Bernoulli GLMM with a logit link function, and then biomass of coral trout on surveys where they were present with a log-normal distribution. The mean expected biomass from the model for a given covariate combination is the product of predicted presence rate and biomass conditional on presence (e.g. Mellin, Russell, Connell, Brook, \& Fordham, 2012).

We modelled both occurrence (i.e. a binary variable for presence/absence), and biomass if present, as functions of three nested random effects and multiple environmental covariates including the long-term mean temperature for a location, the temperature anomaly for that location in the year of the survey, marine protected (MPA) area zone status, percent cover of live hard corals, wave exposure, depth and commercial fishing pressure. The random effects were included to model the spatial hierarchy of sampling and included: surveys (transect scale) within sites, and sites within the fishery logbook reporting grids (0.5 degree grid cells, fig. 1). The MPA zone status was either fished (including restricted fishing 'yellow zones') or no-take ('green zones'). Wave exposure was scored on a three-point scale with $1=$ sheltered from winds in the prevailing direction; 2 = exposure to wind from the prevailing direction; and 3 = exposed to ocean swells. Depth was binned into three categories of $<4$ metres, 4-10 metres, $>10$ metres. Commercial fishing pressure was quantified as the sum of all days of fishing since 2007 in each survey's logbook grid. 
Sea surface temperature data was measured by AVHRR instrument on the NOAA-19 satellites (Integrated Marine Observing System, 2014). We obtained composite (IMOS - SRS - SST - L3C) sea surface temperatures at a daily resolution from night-time passes at a 0.02 by 0.02 degree resolution (L3S dataset, cylindrical equidistant projection) for 2010-2016. We chose this time period to be consistent with the time-period of the UVC data. Validation against ocean buoy data suggests that bias is usually $<0.05^{\circ} \mathrm{C}$ (Integrated Marine Observing System, 2014). We then aggregated the daily data to monthly values by taking the maximum at any given grid cell in each month of each year. Monthly maximums were then resampled to unprojected coordinates, using a bilinear interpolation, and finally aggregated to the scale of the logbook reporting grids again by taking the maximum value. All analyses were performed in the R programming language (3.6.2 Team, 2019) using the packages 'raster' (Hijmans, 2020) and 'sf' (Pebesma, 2018).

The temperature data were pre-analysed to create two covariates representing the mean temperature for each logbook reporting grid (averaging over all days from 2010-2016) and the annual temperature anomaly for the year of the UVC survey. Years were taken as Australian financial years ( $11^{\text {st }}$ July- $30^{\text {th }}$ June) that span summer and are consistent with the reporting of fish catch in Queensland. The anomaly was calculated per grid as the grid's annual mean temperature minus its 2010-2016 mean (fig. 1b \& c). Both temperature covariates were calculated at the scale of the logbook reporting grids to be consistent with the fishery data.

The mean temperature was included to capture spatial gradients of biomass that relate to temperature, the anomaly was included to capture year-to-year responses of biomass to temperature. We also included a term for the interaction between the mean temperature (reflecting latitudinal gradients) and the anomaly. The interaction allowed for our hypothesis that in the year after the heatwave biomass would decrease at northern sites and show little response at southern sites.

The model of biomass did not allow for different performance curves for different coral trout species. However, it is likely that Plectropomus species have similar thermal performance curves. The range midpoint for all five Plectropomus species investigated occurs at average annual temperatures of $22-29^{\circ} \mathrm{C}$ and all three have similar latitudinal extents (Waldock, Stuart-Smith, Edgar, Bird, \& Bates, 2019). Variola spp. tend to occur in warmer waters than Plectropomus spp. (and often a little deeper), but were more rarely observed in the UVC data and are a minor portion of the catch in the commercial fishery (Leigh, Campbell, Lunow, \& O'Neill, 2014).

Seasonal extremes of temperature may have a greater influence on fish range limits than annual means (Stuart-Smith et al 2017), so we compared models that used three different sea temperature metrics. The first metric was the annual mean and annual anomaly, as described above. We also ran models using either March maximum or July minimum sea temperatures to calculate the spatial gradient and anomalies. Comparisons of models fit with the three different temperature measures were made by comparing the models for their leave-one-out cross-validation scores (LOO). The LOO was computed using the efficient 
approximate algorithm (Bürkner, 2018; Vehtari, Gelman, \& Gabry, 2017). Some observations were a poor fit to the approximation, for these we calculated exact cross-validation scores (Bürkner, 2018). Model fits were verified by checking the spread of the Dunn-Smyth residuals of both the occurrence and biomass stages. We also confirmed there was no spatial auto-correlation present in the Dunn-Smyth residuals.

We then sought to estimate how reliably we could extrapolate the biomass predictions to regions with no UVC surveys. After choosing the most parsimonious temperature covariate, we made one more comparison of the full model to a reduced model. The reduced model included only those covariates that were available across the entire GBR (i.e. fixed effects of SST covariates, MPA zone, commercial fishing pressure, and the random effects). The comparison of the full and reduced models was made with the LOO as above.

All models were fitted with the "Bayesian Regression Models using Stan" (brms) R package (Bürkner, 2018), with four chains, where each chain had a warm-up of 1000 iterations and then 2000 samples. We confirmed algorithm convergence with visual checks and the Rhat statistic. We chose conservative priors that promoted shrinkage of effects towards zero, including a $N(0,10)$ prior for fixed effects and $\operatorname{Exp}(1)$ priors for the random effect standard deviations (McElreath, 2020).

We present results as predicted change in expected biomass across the temperature gradients and anomalies. This facilitates interpretation of interactive terms. Other effects were plotted with marginal uncertainty intervals, and we calculated the 2-tailed probability of whether the estimate was different to zero.

\section{Analysis of catch-per-unit effort data}

Fisheries catch data for coral trout were provided by the Queensland Government (State of Queensland Department of Agriculture Fisheries and Forestry, 2020), obtained from mandatory logbooks filled out by commercially licensed fisheries operating in Queensland waters and the Great Barrier Reef Marine Park. Species-specific data for coral trout from the fishery are not considered accurate, but the fishery catch is primarily composed of $P$. leopardus (Leigh et al., 2014). Catch and effort (days of fishing) are available on an annual basis (financial years $1^{\text {st }}$ July $-30^{\text {th }}$ June) since 1990 for the fisheries reporting grids (fig. 1 ). The fishery generally operates in depths $<30$ metres. Grid/year combinations with less than five boats fishing are not available due to data privacy rules.

We next estimated how catchability varied with temperature. We defined catchability as slope of the relationship between biomass and CPUE:

$C P U E_{i, t}=e^{q_{0}} e^{q_{1} T_{i, t}} B_{i, t} e^{\epsilon_{i, t}}$ Equation 1

Where the term $e^{q_{0}} e^{q_{1} T_{i, t}}$ reflected the 'catchability coefficient' with intercept $q_{0}$ and a slope of $q_{1}$ on $\mathrm{T}_{i, t}$, the annual mean sea surface temperature in a grid, $i$, in a year $t . B_{i, t}$ was the unobserved biomass in a grid 
and there are log-normally distributed errors $\epsilon_{i, t}$ on CPUE. If we log this equation, then we have a log-linear model that can be fit using Bayesian regression and a normal distribution on In(CPUE).

Biomass $\left(B_{i, t}\right)$ at the scale of the logbook grids was unknown, so we predicted it from the reduced model of coral trout biomass in UVC surveys. This meant we matched UVC collected at the scale of $500 \mathrm{~m}^{2}$ surveys to the fishery grid cells ( $2900 \mathrm{~km}^{2}$, fig. 1a). The disparity in scale meant it was important to account for uncertainty when scaling-up biomass predictions. So the unknown logbook scale biomass was modelled with a measurement error model:

$\ln \left(B_{i, t}\right)=\ln \left(\overline{B_{l, t}}\right)+z_{i, t}$

Equation 2

Where $\overline{B_{l, t}}$ was the predicted mean grid level biomass, $z_{i, t}$ was an error term taken as the standard error of the posterior predictive estimate of $\overline{B_{l, t}}$ from the biomass model. Predictions for coral trout $\mathrm{kg} / \mathrm{ha}$ were conditional on the grid level random effects, disregarding site level variation. For each grid we then obtained posterior distributions for grid-level biomass by multiplying posterior distributions for $\mathrm{kg} / \mathrm{ha}$ by the grid's area.

The scale matching model had CPUE data from $25 \mathrm{grid} /$ year combinations from 17 logbook grids and spanned an area of 1.22 million ha of reef and $21 \%$ of annual mean catch over 2010-2016. The model was fitted with the 'brms' R package using the measurement error model specification and 18000 samples from 4 chains to achieve convergence. Priors and model verification were as above for the biomass model.

Our hypothesis that temperature directly affects catchability may be invalidated if there were shifts in species composition before and after the heatwave, since different coral trout species may have different catchability. To confirm the dominance of $P$. leopardus, we examined the proportional composition of the biomass of the coral trout taxa observed in the UVC data by species before versus after the heatwave. We plotted composition for two regional covariates: inshore Great Barrier Reef, offshore Great Barrier Reef or Coral Sea, and southern $\left(>20.5^{\circ} \mathrm{S}\right)$, mid $\left(20.5^{\circ} \mathrm{S}-15.3^{\circ} \mathrm{S}\right)$ and northern regions $\left(<15.3^{\circ} \mathrm{S}\right)$. Regions were chosen to ensure a relatively even spread of sites among the different regions and capture known regional variation in species composition. We included an additional 121 Coral Sea sites from (Stuart-Smith et al., 2018) in this analysis, but note these were not included in the model of coral trout biomass because paired CPUE data were lacking.

\section{Analysis of all CPUE data using reef area as a proxy of biomass}

We verified the relationship between CPUE and UVC data by conducting a further analysis on all annual CPUE data from 2011 onwards, giving us a sample size of 461 grid/years (compared to $25 \mathrm{grid} /$ year combinations in the UVC analysis). We chose to use data from 2011 because this recent period has had reasonably stable management regulations (Leigh et al., 2014). For this verification, we included reef area per grid cell as a proxy of coral trout biomass. We also included covariates for cumulative fishing effort 
(days of fishing) over the past five years, as proxies for coral trout biomass. UVC biomass was highly variable across survey sites, and at the scale of the fisheries grids, variation in biomass was primarily driven by the area of reefs (fig S1). Fishing effort is also likely an important driver of spatial patterns in coral trout biomass. The larger sample of data allowed us to consider additional covariates that are known to affect catchability (Leigh et al., 2014). These were number of High-wind Days per year (number of days with mean wind speed over 20 knots) and number of cyclones per year (Bureau of Meteorology, 2020 ). Wind and cyclones were included because coral trout are believed to move deeper than the typical fishing depths after high-wind events (Leigh et al., 2014). We also used historical fishing effort (summed over the past 5 years), area of reef in the grid cell, and a smoother on financial year. High wind days was estimated using the Cross-Calibrated Multi-Platform gridded surface vector winds product, which is an interpolated global wind product that uses a combination of remote and in-situ data (Wentz et al., 2015). We fit this model as a generalized additive mixed model (GAMM, (Wood, 2017)), estimating the effect of each covariate with thin plate smoothing splines. The GAMM framework allowed us to include spatio-temporal random effects, which would capture other spatial gradients in CPUE not related to the covariates. These were individual grid cell level random intercepts and a Gaussian process smooth for grid cell location, with the smooth varying by years (Wood, 2017). The model was fitted using restricted maximum likelihood optimisation and Bayesian credible intervals were estimated as per Wood (2017). We performed stepwise simplification on the full model using the AIC criteria (steps given in Table S1), choosing the model with the lowest AIC for analysis of effect sizes.

\section{Scaling up the impact of the heatwave on fishery catches}

We aimed to estimate the impact of the heatwave on fishery catches during the heatwave year. We first evaluated errors in the prediction of CPUE. We calculated the root-mean-square error by comparing model predictions for $\operatorname{In}$ (CPUE) to observed In(CPUE) for all grid/year combinations with no UVC survey over 20102016. Ln(CPUE) was normalized against the range of $\ln ($ CPUE). As a further comparison we compared predicted catch, based on the 2015-2016 effort distribution to observed catch. These estimates of error are important when interpreting the strength of results of the scaling-up.

To estimate the effect of the heatwave on the total catch of the fishery, we predicted CPUE across all grid cells in the 2015-2016 financial year using temperature conditions from that year. We then multiplied by effort to get the predicted catch distribution for that year. We compare the predicted catch distribution in 2015-2016 against catch predicted for the average (2010-2016) temperature distribution.

\section{Results}

Response of coral trout biomass to the heatwave and other environmental covariates 
Model selection did not discriminate among the three models with annual and seasonal temperature metrics, the LOO was 1622 ( \pm 81.2 S.E.), 1621 ( \pm 81 S.E.), 1622 ( \pm 81.5 S.E.) for the annual average, March maximum and July minimum temperatures respectively. We therefore proceeded with models based on the March maximum, because this matched the season when the heatwave was most severe.

The biomass model had a predictive $\mathrm{R}^{2}$ of $0.30(0.17-0.40,95 \% \mathrm{Cls})$, and the occurrence model had an insample AUC of $0.69(0.62-0.75,95 \% \mathrm{Cls})$. Model verification indicated normality assumptions were satisfied (fig. S1), and that there was no detectable spatial autocorrelation in Dunn-Smyth residuals.
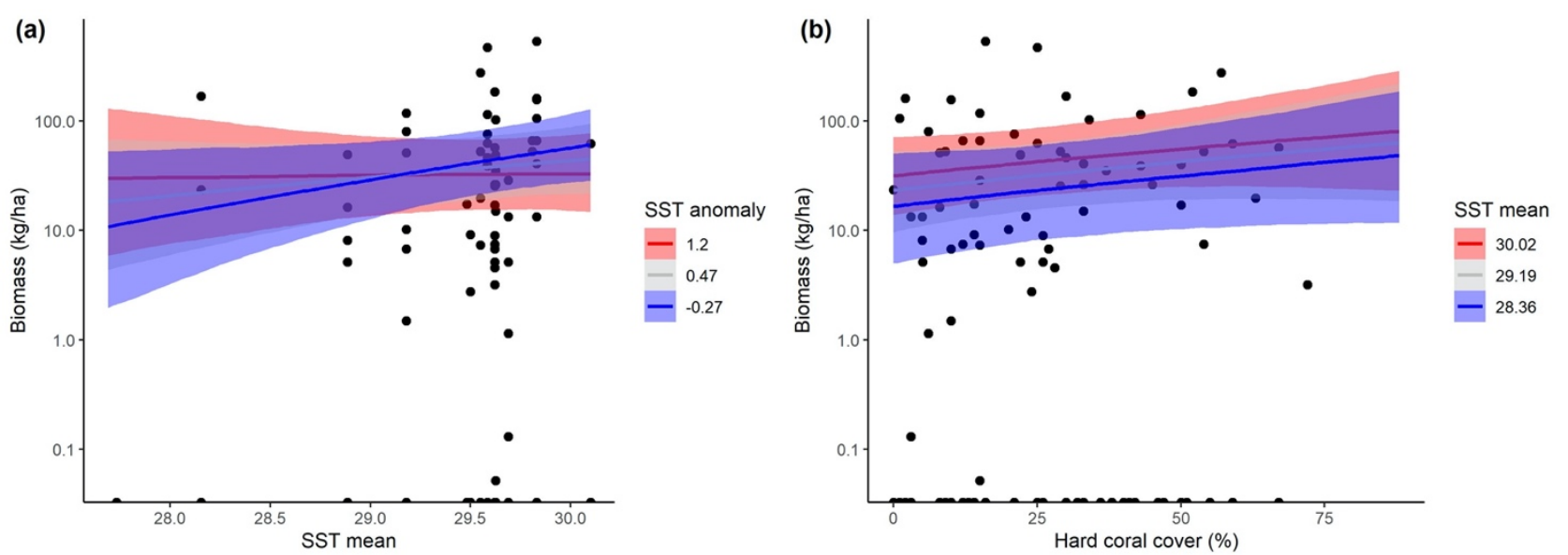

Figure 2 Expected biomass of coral trout on UVC surveys for mean SST and SST anomalies (a) and different levels of coral cover crossed with different mean SST (b).

The expected biomass of coral trout was higher in regions with higher long-term averaged SST, but overall there was high unexplained variation in the biomass trend, so the effect of SST was weak (fig. 2). During the heatwave, the warmer than average SST flattened the gradient of biomass, such that warmer sites were predicted to have slightly lower biomass and cooler sites predicted to have slightly higher biomass (fig. 2). This flattening was indicated by high probability that mean SST and the SST anomaly interacted to affect biomass (probability the effect was $<0=0.94$, fig. 3). There was slightly less evidence for an interactive effect on the occurrence rate (probability the effect was $>0=0.91$, fig. 3). For example, the average temperature anomaly at sampling sites before the heatwave was $-0.1^{\circ}$, whereas during the heatwave it was $+1.0^{\circ}$. Given these anomalies, the models suggested with high probability that coral trout biomass showed regional increases after the heatwave in the coolest fishery grid cells (average SST $27.7^{\circ} \mathrm{C}$; probability = 0.94 ) and decreased in the warmest grid cells (mean SST $30.1^{\circ} \mathrm{C}$; probability $=0.98$ ). The broad uncertainty intervals indicate that this effect was weak relative to other sources of variation (fig. 2). biomass, and only depth affected coral trout occurrence (fig. 3). Coral trout were predicted to occur less frequently in shallower water ( $<4$ metres deep; fig. 3 , prob $>0=0.99)$. 
The reduced model that included only variables available across the GBR had a slightly poorer fit (fig. S1) than the models with the small-scale covariates, however the fit was within the error bounds of the full model LOO estimates ( $L O O=1672, \pm 81.5$ S.E.). The estimates for the effect of the temperature anomaly in the reduced model were similar to the full model (fig. S2).

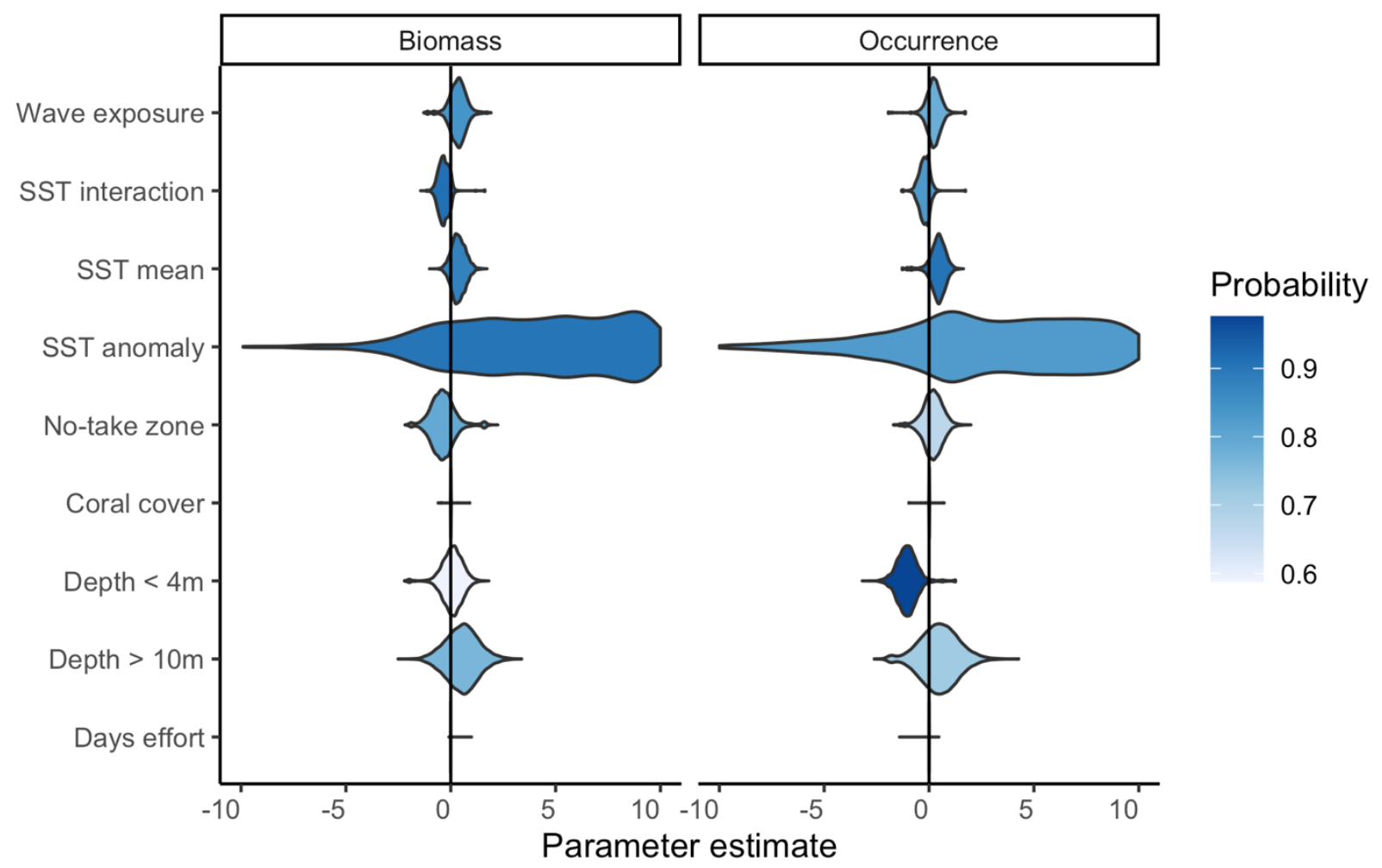

Figure 3 Distributions of the marginal parameter estimates from the environmental model of coral trout biomass (A) and occurrence (B). Colours indicate two tailed probabilities of $x>0$ or $x<0$, where darker colours indicate a higher probability the parameter estimate is different from zero. Note the $x$-axis is truncated at +10 , the SST anomaly parameter estimates had long positive tails.

\section{Catchability in relation to underwater biomass data and SST}

The estimates of UVC biomass for whole CPUE grid cells had a positive relationship with reef area, which flattened for reef areas $>500 \mathrm{~km}^{2}$ (fig. S3). Across all grid cells with coral-trout catch, CPUE was positively related to reef area (fig. S4).

CPUE was positively related to the estimates of mean in-water biomass (fig. 4; slope of $0.93,0.57$ to 1.34 , 95\% Cls, fit to data shown in fig. S5). Deviations in the relationship between CPUE and in-water biomass were consistent with a positive effect of temperature on catchability (fig. 4, fit to data in fig. S6), with an average increase in CPUE of 1.4 times per 1 S.D. increase in temperature (1.08 to $1.78,95 \% \mathrm{Cls}$ ) and a probability of 0.999 that the SST effect increased CPUE. For instance, at a biomass of 500 tonnes (per grid cell) there was a 0.003 probability that CPUE was $>0.03$ tonnes/day at average temperatures but 0.89 
probability that CPUE $>0.03$ for a temperature 1 S.D. $\left(=0.98^{\circ} \mathrm{C}\right)$ above average. The increase in catchability under warming meant that more catch can be taken with an equal amount of effort in warmer years, or the same amount of catch can be taken with less effort (fig. 4).

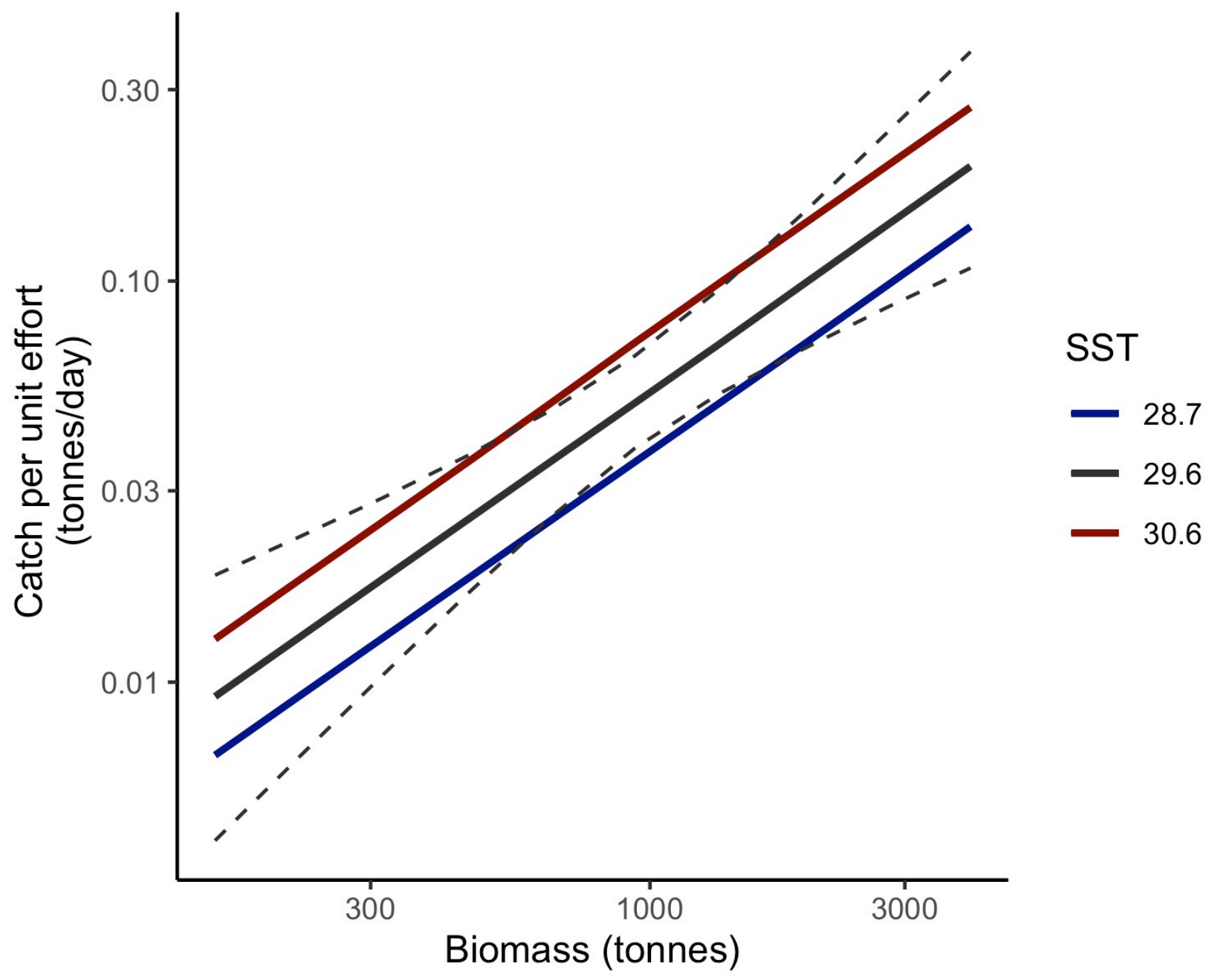

Figure 4 Predicted relationship between grid-level expected biomass predictions and CPUE under different temperatures. Colours represent SST values (mean \pm 1 S.D.), $95 \% \mathrm{Cls}$, are given as dashed lines for just the mean SST for clarity of presentation.

341 We confirmed that the catchability change could not be explained by shifts in species composition.

342 Plectropomus leopardus was the dominant coral trout species on underwater censuses across most of the 343 Great Barrier Reef region (fig. S7), while Plectropomus laevis dominated at Coral Sea sites and Plectropomus 344 maculatus dominated at inshore southern sites. There was no significant change in the dominant species 345 before versus after the heatwave for any region, although $P$. laevis became slightly more common as $P$. 346 leopardus declined at northern offshore Great Barrier Reef and northern Coral Sea sites (which do not 347 overlap with the fishery data). 
The analysis relating all available CPUE data back to 2011 to reef area (a proxy of biomass) and other environmental covariates indicated that a model with a non-linear effect of reef area, linear effect of SST, non-linear effect of year, and a spatial smooth that varied by years was optimal (Table S1). Wind and cyclones were not important predictors of annual CPUE. The effect of area indicated increasing catch rates up to a maximum at a reef area of $400 \mathrm{~km}^{2}$ (fig. S4). Increases in SST in a grid in a year also increased CPUE by a multiple that was of similar magnitude to that estimated by the UVC model: 1.32 times (fig. S7, 1.1 to $1.63,95 \% \mathrm{Cls}$ ). The probability SST was associated with increased CPUE was also $>0.999$.

Scaling-up catch estimates for 2016

Total catch in the grid cells with data for the 2015-2016 financial year was reported to be 850 tonnes. Transforming the predicted CPUE in all grid cells and using the 2015-2016 effort distribution gave an expected catch of 798 tonnes (368-1934 tonnes, 95\% Cls). This estimate accounted for uncertainty in the grid level biomass estimates. The root mean square error for predictions of $\ln (\mathrm{CPUE})$ in grid squares that did not have a UVC survey was 1.41 , or error that was $30 \%$ of the range of $\ln$ (CPUE) values (20-54\%, $95 \%$ Cls). The error was high because of uncertainty in biomass and the estimated catchability coefficient.

When predictions were made conditional on the mean UVC biomass, the CPUE model predicted a catch of 805 tonnes in 2015-2016 (544-1224 tonnes, 95\% Cls). The catch estimate was reduced to 680 tonnes (4641018 tonnes, 95\% Cls) when predictions were made using average March temperatures over 2010-2016. Thus, the model predicted catches during the heatwave year were $18 \%$ higher than under average temperatures for the same amount of fishing effort. The greatest predicted effect of the heatwave on catch was in the Northern and mid-GBR (fig. 5), where the temperature anomaly was the greatest (fig. 1). In the north there was a high certainty of a positive effect of the heatwave on catches ( $95 \%$ C.Is >0, fig. 5), whereas in the south there was lower certainty as to the direction of the effect of the heatwave on catches (95\% C.Is close to zero, fig. 5).

The effect of the heatwave was not evident in the overall spatial pattern of catch in 2015-2016, which were largely consistent with earlier years (fig. S9). This suggests increases in catchability were compensated for by reduced fishing effort. 

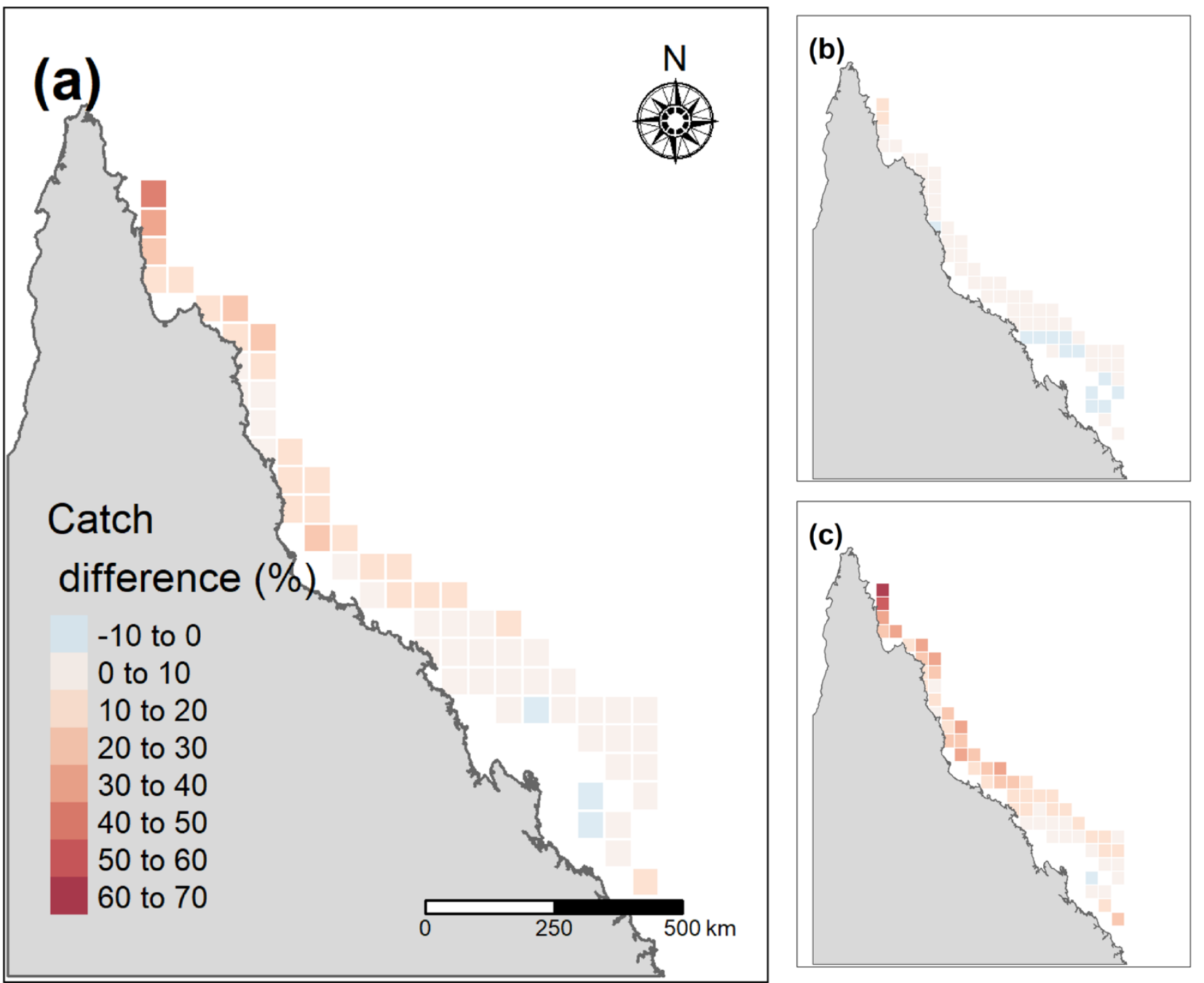

Figure 5 Expected difference in catch (\%) during the heatwave year (2016) from mean temperature conditions. A, B, C show median and lower and upper $95 \%$ probability quantiles. Predictions were made assuming coral trout biomass was fixed at its mean for each fishery grid.

\section{Discussion}

The most significant effect of the heatwave on coral trout that we observed was a higher catch per unit effort where biomass had declined following the heatwave, caused by an increase in catchability. The increase in catchability could have many causes, but is consistent with experimental studies that have tested the physiological tolerance of coral trout to warming. Warming affects multiple physiological and behavioural traits that we hypothesize are related to catchability. Warming increases metabolic needs of individual fish, who respond by increasing their feeding rates (Johansen et al., 2015). Higher feeding rates in warmer seas may explain the increase in catchability: the reef line fishery uses bait or lures to catch fish (Leigh et al., 2014), so fish may be more likely to take the line if they are feeding at a higher rate. Warming to the extent that occurred in the heatwave reduces spontaneous swimming speed (Johansen, Messmer, Coker, Hoey, \& Pratchett, 2014), and warmer climates and seasons are also associated with smaller home ranges (Scott, Heupel, Simpfendorfer, Matley, \& Pratchett, 2019). Swimming speed and home range size 
may both affect the likelihood that coral trout take bait or lures. Further work is needed to test how changes in these behavioural traits affect fish preferences for bait versus wild prey, which may be harder to catch.

Three alternate hypotheses for the causes of these changes in catchability include foraging efficiency, prey availability and species turnover, all of which we consider less likely than physiologically mediated impacts on catchability. First, loss of coral habitats may impact feeding success by coral trout (Hempson et al., 2017), which could presumably affect their catchability in the fishery. It has been proposed that the likelihood of coral trout taking bait or lures is lower after loss of structurally complex corals because it is easier for coral trout to catch their prey (Brown, Taylor, Wabnitz, \& Connolly, 2020; Leigh et al., 2014). However, this hypothesis predicts declines in catchability following coral loss, the opposite pattern to what we observed.

Second, declines in structurally complex coral may also see a reduction in prey fishes, increasing the likelihood that coral trout take bait or lures. This process is most likely to affect coral trout over longer time-scales than our study, because it requires erosion of reef structure to impact prey fishes. It is also unlikely to impact such flexible predators as coral trout. Populations of $P$. maculatus can switch to feeding through entirely different trophic pathways following coral degradation (Hempson et al., 2017). No widespread changes in potential prey items (small fishes) were observed in the UVC data as a result of the heatwave (although a subset of highly coral-dependent species suffered on the worst hit reefs)(StuartSmith et al., 2018), and it is unlikely trout would be found at sites where they were food limited. Longerterm degradation of coral will cause changes in food webs that may impact coral trout populations (Hempson et al., 2017; Rogers et al., 2018) but we suggest that the major impact on fisheries would be noticed through changes in occurrence and biomass rather than changes in catchability.

A third hypothesis we can exclude is that changes in the relative proportions of the different coral trout species to the catch could also affect the overall catchability for the fishery. Our models predicted the greatest increase in catchability on northern reefs, which remained dominated in the UVC data by $P$. leopardus both before and after the heatwave (Fig. S8). Inshore northern reefs saw a decline in the biomass of $P$. maculatus relative to other coral trout species and it is possible this change in species composition may have contributed to changes in catchability if this species was harder to catch than the others. We are not aware of any evidence documenting that coral trout species vary in their catchability in line fisheries, but fish catch data resolved to the species level could help future studies to address this knowledge gap.

We also observed that coral trout biomass was reduced after the heatwave in warmer low latitude reefs, but was stable or slightly increasing on cooler high latitude reefs. The model suggested that the decline in biomass was attributed to the temperature anomaly, rather than fishing pressure, but the high variability in predictions suggests further data are needed to confirm the effects of temperature on coral trout biomass 
on the GBR. Further, it is unclear from this data if biomass changes were caused by migration or increased mortality. Coral trout population productivity may be sensitive to climate warming, and vulnerable to decline in low latitude locations that are already close to coral trout upper thermal limits (Stuart-Smith et al., 2017). Effects of high temperatures observed for coral trout species include reduced aerobic scope, swimming speeds and survival at temperatures from $27-30^{\circ} \mathrm{C}$ (Pratchett et al., 2017). These observations from laboratory studies are consistent with our finding that declining biomass may have occurred at the northern most edge of the range, where mean summer temperatures are close to $30^{\circ} \mathrm{C}$ and the heatwave raised temperatures by $\sim 1^{\circ} \mathrm{C}$ (Wolanski et al., 2017). At higher latitudes, where typical temperatures are below the thermal optimal for coral trout, heatwaves may enhance coral trout survival and contribute to higher recruitment of early life-stage individuals (Bornt et al., 2015).

A caveat to our finding of reduced biomass is that behavioural change may also affect UVC estimates of biomass. Some fishes may respond to warming by migrating to deeper, cooler water (Dulvy et al., 2008), and coral trout are believed to migrate deeper in response to other extreme weather events, like cyclones (Leigh et al., 2014). However, it is unlikely that the reduction in biomass observed is indicative of coral trout migrating to reefs beyond the span of the UVC surveys, because coral trout are most common down to depths of $20 \mathrm{~m}$ (Leigh et al., 2014) and the UVC surveys included surveys to $17 \mathrm{~m}$ (Stuart-Smith et al., 2018). Home range size also changes in response to temperature (Scott et al., 2019), and home-range size may affect the likelihood of detecting fish on UVC surveys, though it is not clear in what direction. Electronic tagging studies (e.g. Scott et al., 2019) and paired catch-UVC studies (Bacheler \& Shertzer, 2020) would help identify the mechanism for reduced biomass at warm sites.

Some coral trout species make use of live coral habitat for settlement (Wen et al., 2013) and feed on prey that use coral habitat (John, Russ, Brown, \& Squire, 2001), so coral loss could cause declines in coral trout biomass over longer timespans than the duration of this study. Temperature may also impact spawning behaviour and affect fertilization and therefore numbers of settlers (Pratchett et al., 2017). Settling $P$. maculatus rely on structured corals for shelter, with enhanced recruitment in areas with higher live coral cover (Wen et al., 2013). Given the age at first breeding for coral trout is 2-3 years and that adult biomass is dominated by older age-classes, the impacts of reduced coral cover on adult biomass are unlikely to manifest for $>5$ years (Brown et al., 2020). The dependency of coral trout on coral may expose the productivity of the fishery to the multiple stressors, including poor water quality and climate warming, that are currently causing coral declines and hindering coral recovery (Mellin et al., 2019; Wolff, Mumby, Devlin, \& Anthony, 2018). Continuing monitoring is needed to understand the magnitude of coral habitat loss effects on coral trout over longer timescales than were studied here.

Global warming could potentially affect sustainability of the coral trout fishery if heatwave-induced spikes in catchability are not accounted for in stock assessments. Currently, heatwave events of the magnitude observed in 2016 are predicted to occur every 3 years; with 1.5 degrees of global warming, 2016-like events 
may occur more often than every 2 years on average (King, Karoly, \& Henley, 2017). Since 2016, the GBR has experienced successive heatwaves in 2017 and 2020. The management regime of the reef line fishery is likely robust to infrequent changes in catchability of the magnitude we observed because catches are well below the maximum sustainable yield (Campbell, Leigh, Bessel-Browne, \& Lovett, 2019). The existing management regime that mixes marine parks and catch quotas is also robust to regional variation in ecological dynamics (Bode, Sanchirico, \& Armsworth, 2016), overfishing (Hopf et al., 2016; Little et al., 2011) and climatic change (Hopf, Jones, Williamson, \& Connolly, 2019). A stock assessment conducted in 2014, which utilized UVC and CPUE data, did not find any effects of coral bleaching events on stock productivity, and environmental change was found to have limited impact on the fishery (Leigh et al., 2014). Regardless, this may not be the case in future. If contemporary 3-yearly spikes in catchability are combined with productivity declines due to loss of recruitment habitat (Brown et al., 2020), the stock may become susceptible to overfishing. Continued monitoring of coral trout biomass is needed to assess the impacts recurrent heatwaves on catchability, so we can quantify the cumulative effects of multiple heatwave events, which may be non-linear. The recreational catch of coral trout adds further uncertainty (see below), and future increases in recreational effort could also take stocks to the point where catchability changes induced by warmer seas could be critical. The latest stock assessment identified that accounting for environmental change, including heatwaves, is a priority for future stock assessments (Campbell et al., 2019).

Stock assessments, including stock parameter estimates, need updating more frequently in fisheries subject to rapid environmental change, regardless of the ecological causes of population responses to environmental change (Brown, Fulton, Possingham, \& Richardson, 2012). For instance, the total current allowable catch in the reef line fishery is set on the basis of the ratio between current CPUE and a target CPUE (The State of Queensland, 2017), but this ratio assumes a constant linear relationship between CPUE and biomass. More generally than Australia, coral trout are caught in many tropical reef fisheries, but those fisheries are typically poorly regulated and often overfished (Frisch et al., 2016), and increasing catchability would only be expected to worsen overfishing. Our results indicate that this assumption is only reasonable in the absence of changing environmental temperatures, and highlights the critical importance of fishery independent data for informing stock assessments.

An important caveat to our analysis is that we did not consider the impact of the recreational fishery on biomass or the effects of heatwaves on catchability in the recreational fishery. Overall, recreational fishing made up a minority of the catch in the 2017-2018 financial year (estimated at 17\% of total catch (Campbell et al., 2019)), but its effects may be locally intense. The recreational fishery targets coral trout with line fishing and spearfishing. Line fishing is likely to be subject to similar increases in catchability during heatwaves as we observed here, whereas it is unclear how high temperatures would affect catchability by spear fishers. Data from the recreational fishery are only collected intermittently and are not spatially 
resolved for detailed use in analyses such as those undertaken here (Webley, McInnes, Teixeira, Lawson, \& Quinn, 2015). Future research would usefully directly involve recreational fishers to better understand factors affecting catchability.

Globally, fisheries are highly susceptible to climate change, potentially negatively affecting food security and livelihoods of hundreds of millions of people (Cheung et al., 2010). While the predominant research focus has been on impacts of habitat loss on coral reef fish assemblage composition and productivity (e.g. Hopf et al., 2019; Robinson et al., 2019), our study adds to the evidence that temperature-driven changes in catchability are important to consider in reef fishery management (Bacheler \& Shertzer, 2020). We suggested here that changes in catchability are heavily influenced by mechanisms stemming from physiological responses to warming, but we recommend further experimental studies to explore ecological mechanisms that may independently involve changes in prey or habitat. Increases in catchability during heatwaves similar to that found for coral trout may also be widespread globally, given the prevalence of line and trap capture methods amongst coral reef fisheries. To avoid collapses induced by environmental change, fisheries management should use data on stock biomass that are independent of fishery catches. Our work highlights the importance of fisheries-independent data, which unfortunately are not collected for most reef fisheries (Pauly \& Zeller, 2016), and precautionary management that is adaptive to climate change to sustain reef fisheries into the future.

\section{Acknowledgements}

CJB was supported by a Discovery Early Career Researcher Award (DE160101207). We thank Reef Life Survey (RLS) divers and boat skippers who assisted with field surveys, including D. and J. Shields, I. Donaldson and S. Griffiths, and A. Cooper, J. Berkhout and E. Clausius at the University of Tasmania for logistics and data management. Funding and support for the GBR and Coral Sea RLS field surveys were provided by The lan Potter Foundation and Parks Australia. Permits were provided by Parks Australia and the Great Barrier Reef Marine Park Authority. The SST data and the RLS data management is supported by Australia's integrated marine observing system (IMOS). IMOS is enabled by the national collaborative research infrastructure strategy (NCRIS). It is operated by a consortium of institutions as an unincorporated joint venture, with the University of Tasmania as lead agent. The authors are grateful to the Queensland Government for providing open-access data on fisheries harvest through the QFish portal.

\section{References}

Auth, T. D., Daly, E. A., Brodeur, R. D., \& Fisher, J. L. (2018). Phenological and distributional shifts in ichthyoplankton associated with recent warming in the northeast Pacific Ocean. Global Change Biology, 24(1), 259-272. doi:10.1111/gcb.13872 
Bacheler, N. M., \& Shertzer, K. W. (2020). Catchability of reef fish species in traps is strongly affected by water temperature and substrate. Marine Ecology Progress Series, 642, 179-190.

Belhabib, D., Dridi, R., Padilla, A., Ang, M., \& Le Billon, P. (2018). Impacts of anthropogenic and natural "extreme events" on global fisheries. Fish and Fisheries, 19(6), 1092-1109. doi:10.1111/faf.12314

Bell, J. D., Ganachaud, A., Gehrke, P. C., Griffiths, S. P., Hobday, A. J., Hoegh-Guldberg, O., . . Lough, J. M. (2013). Mixed responses of tropical Pacific fisheries and aquaculture to climate change. Nature Climate Change, 3(6), 591.

Bode, M., Sanchirico, J. N., \& Armsworth, P. R. (2016). Returns from matching management resolution to ecological variation in a coral reef fishery. Proceedings of the Royal Society B: Biological Sciences, 283(1826), 20152828. doi:doi:10.1098/rspb.2015.2828

Bornt, K. R., McLean, D. L., Langlois, T. J., Harvey, E. S., Bellchambers, L. M., Evans, S. N., \& Newman, S. J. (2015). Targeted demersal fish species exhibit variable responses to long-term protection from fishing at the Houtman Abrolhos Islands. Coral Reefs, 34(4), 1297-1312. doi:10.1007/s00338-015$1336-5$

Brander, K. (2010). Impacts of climate change on fisheries. Journal of Marine Systems, 79(3-4), 389-402.

Brown, C. J., Fulton, E. A., Possingham, H. P., \& Richardson, A. J. (2012). How long can fisheries management delay action in response to ecosystem and climate change? Ecological Applications, 22(1), 298-310.

Brown, C. J., Taylor, W., Wabnitz, C. C. C., \& Connolly, R. M. (2020). Dependency of tropical fisheries on reef-associated fish: insights from Queensland and the Great Barrier Reef Scientific reports, 10 , 17801.

Bureau of Meteorology. (2020). Australian Tropical Cyclone Database. Retrieved from: http://www.bom.gov.au/cyclone/tropical-cyclone-knowledge-centre/databases/

Burke, L., Reytar, K., Spalding, M., \& Perry, A. (2011). Reefs at risk revisited: World Resources Institute. Bürkner, P.-C. (2018). Advanced bayesian multilevel modeling with the R package brms. The R Journal, 10, 395-411. doi:doi.org/10.32614/RJ-2018-017 
Campbell, A., Leigh, G., Bessel-Browne, P., \& Lovett, R. (2019). Stock assessment of the Queensland east coast common coral trout (Plectropomus leopardus) fishery. April 2019. Retrieved from Brisbane: http://era.daf.qld.gov.au/id/eprint/7009/

Caputi, N., Kangas, M. I., Chandrapavan, A., Hart, A., Feng, M., Marin, M., \& de Lestang, S. (2019). Factors affecting the recovery of invertebrate stocks from the 2011 Western Australian extreme marine heatwave. Frontiers in Marine Science, 6, 484.

Cheung, W. W., Lam, V. W., Sarmiento, J. L., Kearney, K., Watson, R., Zeller, D., \& Pauly, D. (2010). Largescale redistribution of maximum fisheries catch potential in the global ocean under climate change. Global Change Biology, 16(1), 24-35.

Darling, E. S., McClanahan, T. R., Maina, J., Gurney, G. G., Graham, N. A. J., Januchowski-Hartley, F., . . . Mouillot, D. (2019). Social-environmental drivers inform strategic management of coral reefs in the Anthropocene. Nature Ecology \& Evolution, 3(9), 1341-1350. doi:10.1038/s41559-019-0953-8

Dulvy, N. K., Rogers, S. I., Jennings, S., Stelzenmüller, V., Dye, S. R., \& Skjoldal, H. R. (2008). Climate change and deepening of the North Sea fish assemblage: a biotic indicator of warming seas. Journal of Applied Ecology, 45(4), 1029-1039.

Edgar, G. J., Barrett, N. S., \& Morton, A. J. (2004). Biases associated with the use of underwater visual census techniques to quantify the density and size-structure of fish populations. Journal of Experimental Marine Biology and Ecology, 308(2), 269-290.

Edgar, G. J., \& Stuart-Smith, R. D. (2014). Systematic global assessment of reef fish communities by the Reef Life Survey program. Scientific Data, 1(1), 1-8.

Ferrari, R., Bryson, M., Bridge, T., Hustache, J., Williams, S. B., Byrne, M., \& Figueira, W. (2016). Quantifying the response of structural complexity and community composition to environmental change in marine communities. Global Change Biology, 22(5), 1965-1975.

Free, C. M., Thorson, J. T., Pinsky, M. L., Oken, K. L., Wiedenmann, J., \& Jensen, O. P. (2019). Impacts of historical warming on marine fisheries production. Science, 363(6430), 979-983. doi:10.1126/science.aau1758 
Frisch, A. J., Cameron, D. S., Pratchett, M. S., Williamson, D. H., Williams, A. J., Reynolds, A. D., . . Kerrigan, B. (2016). Key aspects of the biology, fisheries and management of coral grouper. Reviews in Fish Biology and Fisheries, 26(3), 303-325.

GBRMPA. (2019). Great Barrier Reef Outlook Report 2019: Great Barrier Reef Marine Park Authority.

Graham, N., \& Nash, K. (2013). The importance of structural complexity in coral reef ecosystems. Coral Reefs, 32(2), 315-326. doi:10.1007/s00338-012-0984-y

Graham, N. A., Wilson, S. K., Jennings, S., Polunin, N. V., Robinson, J., Bijoux, J. P., \& Daw, T. M. (2007). Lag effects in the impacts of mass coral bleaching on coral reef fish, fisheries, and ecosystems. Conservation Biology, 21(5), 1291-1300.

Hamilton, R. J., Almany, G. R., Stevens, D., Bode, M., Pita, J., Peterson, N. A., \& Choat, J. H. (2016). Hyperstability masks declines in bumphead parrotfish (Bolbometopon muricatum) populations. Coral Reefs, 35(3), 751-763. doi:10.1007/s00338-016-1441-0

Hempson, T. N., Graham, N. A., MacNeil, M. A., Williamson, D. H., Jones, G. P., \& Almany, G. R. (2017). Coral reef mesopredators switch prey, shortening food chains, in response to habitat degradation. Ecology and evolution, 7(8), 2626-2635.

Hijmans, R. J. (2020). raster: Geographic Data Analysis and Modeling version 3.0-12. Retrieved from https://CRAN.R-project.org/package=raster

Hopf, J. K., Jones, G. P., Williamson, D. H., \& Connolly, S. R. (2016). Synergistic effects of marine reserves and harvest controls on the abundance and catch dynamics of a coral reef fishery. Current Biology, 26(12), 1543-1548.

Hopf, J. K., Jones, G. P., Williamson, D. H., \& Connolly, S. R. (2019). Marine reserves stabilize fish populations and fisheries yields in disturbed coral reef systems. Ecological Applications, 29(5), e01905. doi:10.1002/eap.1905

Hughes, T. P., Kerry, J. T., Baird, A. H., Connolly, S. R., Dietzel, A., Eakin, C. M., . . Liu, G. (2018). Global warming transforms coral reef assemblages. Nature, 556(7702), 492.

Integrated Marine Observing System. (2014). IMOS - SRS - SST - L3C - NOAA 19 - 1 day - night time Australia. Retrieved from: https://catalogue- 
imos.aodn.org.au:443/geonetwork/srv/en/metadata.show?uuid=46ebc1a9-c503-4435-b85c-

\section{$\underline{11 \mathrm{fe} 16176 \mathrm{c} 8 \mathrm{~d}}, \underline{\text { https://researchdata.edu.au/imos-srs-sst-time-australia }}$}

Johansen, J., Pratchett, M., Messmer, V., Coker, D. J., Tobin, A., \& Hoey, A. (2015). Large predatory coral trout species unlikely to meet increasing energetic demands in a warming ocean. Scientific reports, $5,13830$.

Johansen, J. L., Messmer, V., Coker, D. J., Hoey, A. S., \& Pratchett, M. S. (2014). Increasing ocean temperatures reduce activity patterns of a large commercially important coral reef fish. Global Change Biology, 20(4), 1067-1074. doi:10.1111/gcb.12452

John, J. S., Russ, G. R., Brown, I. W., \& Squire, L. C. (2001). The diet of the large coral reef serranid Plectropomus leopordus in two fishing zones on the Great Barrier Reef, Australia. Fishery Bulletin, 99(1), 180-180.

King, A. D., Karoly, D. J., \& Henley, B. J. (2017). Australian climate extremes at 1.5 C and 2 C of global warming. Nature Climate Change, 7(6), 412-416.

Lefcheck, J. S., Wilcox, D. J., Murphy, R. R., Marion, S. R., \& Orth, R. J. (2017). Multiple stressors threaten the imperiled coastal foundation species eelgrass (Zostera marina) in Chesapeake Bay, USA. Global Change Biology, 23(9), 3474-3483.

Leigh, G. M., Campbell, A. B., Lunow, C. P., \& O'Neill, M. F. (2014). Stock assessment of the Queensland east coast common coral trout (Plectropomus leopardus) fishery. Retrieved from Brisbane, Queensland: http://era.daf.qld.gov.au/id/eprint/7009/

Little, L., Grafton, R., Kompas, T., Smith, A., Punt, A., \& Mapstone, B. (2011). Complementarity of no-take marine reserves and individual transferable catch quotas for managing the line fishery of the Great Barrier Reef. Conservation Biology, 25(2), 333-340.

McElreath, R. (2020). Statistical rethinking: A Bayesian course with examples in R and Stan: CRC press.

Mellin, C., Matthews, S., Anthony, K. R. N., Brown, S. C., Caley, M. J., Johns, K. A., . . MacNeil, M. A. (2019). Spatial resilience of the Great Barrier Reef under cumulative disturbance impacts. Global Change Biology, 25(7), 2431-2445. doi:10.1111/gcb.14625 
Mellin, C., Russell, B. D., Connell, S. D., Brook, B. W., \& Fordham, D. A. (2012). Geographic range determinants of two commercially important marine molluscs. Diversity and Distributions, 18(2), 133-146. doi:10.1111/j.1472-4642.2011.00822.x

Oliver, E. C., Donat, M. G., Burrows, M. T., Moore, P. J., Smale, D. A., Alexander, L. V., .. . Hobday, A. J. (2018). Longer and more frequent marine heatwaves over the past century. Nature Communications, 9(1), 1-12.

Patterson, K., Pitcher, T., \& Stokes, T. (1993). A stock collapse in a fluctuating environment: the chub mackerel Scomber japonicus (Houttuyn) in the eastern central Pacific. Fisheries Research, 18(3-4), 199-218.

Pauly, D., \& Zeller, D. (2016). Catch reconstructions reveal that global marine fisheries catches are higher than reported and declining. Nature Communications, 7, 10244.

Pebesma, E. (2018). Simple Features for R: Standardized Support for Spatial Vector Data. The R Journal, 10, 439-446. doi:10.32614/RJ-2018-009

Pratchett, M. S., Cameron, D. S., Donelson, J., Evans, L., Frisch, A. J., Hobday, A. J., . . Munday, P. L. (2017). Effects of climate change on coral grouper (Plectropomus spp.) and possible adaptation options. Reviews in Fish Biology and Fisheries, 27(2), 297-316.

Pratchett, M. S., Munday, P. L., Wilson, S. K., Graham, N. A., Cinner, J. E., Bellwood, D. R., . . McClanahan, T. R. (2008). Effects of climate-induced coral bleaching on coral-reef fishes-ecological and economic consequences. In Oceanography and Marine Biology (pp. 257-302): CRC Press.

Richardson, L. E., Graham, N. A., Pratchett, M. S., Eurich, J. G., \& Hoey, A. S. (2018). Mass coral bleaching causes biotic homogenization of reef fish assemblages. Global Change Biology, 24, 3117-3129.

Robinson, J. P., Wilson, S. K., Robinson, J., Gerry, C., Lucas, J., Assan, C., . . Graham, N. A. (2019). Productive instability of coral reef fisheries after climate-driven regime shifts. Nature Ecology \& Evolution, 3(2), 183.

Rogers, A., Blanchard, J. L., \& Mumby, P. J. (2018). Fisheries productivity under progressive coral reef degradation. Journal of Applied Ecology, 55(3), 1041-1049. 
Scott, M. E., Heupel, M. R., Simpfendorfer, C. A., Matley, J. K., \& Pratchett, M. S. (2019). Latitudinal and seasonal variation in space use by a large, predatory reef fish, Plectropomus leopardus. Functional Ecology, 33(4), 670-680.

Smale, D. A., Wernberg, T., Oliver, E. C. J., Thomsen, M., Harvey, B. P., Straub, S. C., . . Moore, P. J. (2019). Marine heatwaves threaten global biodiversity and the provision of ecosystem services. Nature Climate Change, 9(4), 306-312. doi:10.1038/s41558-019-0412-1

State of Queensland Department of Agriculture Fisheries and Forestry. (2020). QFish data cube. Retrieved from https://qfish.fisheries.qld.gov.au/

Stuart-Smith, R. D., Brown, C. J., Ceccarelli, D. M., \& Edgar, G. J. (2018). Ecosystem restructuring along the Great Barrier Reef following mass coral bleaching. Nature, 560, 92-96.

Stuart-Smith, R. D., Edgar, G. J., \& Bates, A. E. (2017). Thermal limits to the geographic distributions of shallow-water marine species. Nature Ecology \& Evolution, 1(12), 1846.

Team, R. C. (2019). R: A Language and Environment for Statistical Computing. Retrieved from https://www.R-project.org/

The State of Queensland. (2017). Fisheries (Coral Reef Fin Fish) QuotaAmendment Declaration, Explanatory Notes for SL 2017 No. 56. Retrieved from Brisbane, Queensland: www. legislation.qld.gov.au

Vehtari, A., Gelman, A., \& Gabry, J. (2017). Practical Bayesian model evaluation using leave-one-out crossvalidation and WAIC. Statistics and Computing, 27(5), 1413-1432.

Waldock, C., Stuart-Smith, R. D., Edgar, G. J., Bird, T. J., \& Bates, A. E. (2019). The shape of abundance distributions across temperature gradients in reef fishes. Ecology Letters, 22(4), 685-696.

Webley, J., McInnes, K., Teixeira, D., Lawson, A., \& Quinn, R. (2015). 2014 Statewide Recreational Fishing Survey. Retrieved from Brisbane, Queensland:

Wen, C., Pratchett, M., Almany, G., \& Jones, G. (2013). Patterns of recruitment and microhabitat associations for three predatory coral reef fishes on the southern Great Barrier Reef, Australia. Coral Reefs, 32(2), 389-398. doi:10.1007/s00338-012-0985-x 
Wentz, F., Scott, J., Hoffman, R., Leidner, M., Atlas, R., \& Ardizzone, J. (2015). Remote Sensing Systems Cross-Calibrated Multi-Platform (CCMP) 6-hourly ocean vector wind analysis product on 0.25 deg grid, Version 2.0. Remote Sensing Systems, Santa Rosa, CA. Data from 2011-2016.

Wilberg, M. J., Thorson, J. T., Linton, B. C., \& Berkson, J. (2009). Incorporating time-varying catchability into population dynamic stock assessment models. Reviews in Fisheries Science, 18(1), 7-24.

Wolanski, E., Andutta, F., Deleersnijder, E., Li, Y., \& Thomas, C. (2017). The Gulf of Carpentaria heated Torres Strait and the Northern Great Barrier Reef during the 2016 mass coral bleaching event. Estuarine, Coastal and Shelf Science, 194, 172-181.

Wolff, N. H., Mumby, P. J., Devlin, M., \& Anthony, K. R. N. (2018). Vulnerability of the Great Barrier Reef to climate change and local pressures. Global Change Biology, 24(5), 1978-1991. doi:10.1111/gcb.14043

Wood, S. N. (2017). Generalized additive models: an introduction with R: CRC press. 